\title{
DETERMINAN PEMANFAATAN PUSKESMAS PADA ANAK PENYANDANG DISABILITAS
}

DIFABLE CHILDREN UTILIZATION DETERMINANTS OF PUBLIC HEALTH CENTER

Orin Annahriyah Syukria, Stefanus Supriyanto

Fakultas Kesehatan Masyarakat, Universitas Airlangga

E-mail: orina.abas@gmail.com

\begin{abstract}
People with disability are the largest minority group. WHO informs that the group mostly stay in developing country and one third of them are children. People with disability reported to have less access to health care than common society. The objective of this study was to describe the factors possibly influencing the primary health care access of children with disability in Gubeng and Mulyorejo subdistrict, Surabaya, as the one of region in East Java that reported to have not been accomodate the needs of disabled people. It was cross sectional study with observasional approach. Participants of this study were 160 children with disability along with their parents that choosen by purposive sampling. Half of population were visited and among them obtained 44 samples. The results showed that the variables significantly related to the access of primary health care were the kind of disabilty, activity of daily living value, distance between the house and health care, transportation, parents income, health cost and transportation cost. Either individual or environtmental factor could be known as the factor that related to the access of health care in children with disability.
\end{abstract}

Keywords: Activity of daily living, disability, environtmental factors, health care access

\section{PENDAHULUAN}

Anak merupakan kelompok umur yang rentan terhadap berbagai masalah. Hal ini antara lain disebabkan oleh kemampuan anakyang masih rendah dalam mengelola tindakan dan emosi dari diri sendiri. Anak belum dapat sepenuhnya memahami hal yang terjadi di sekitarnya dan kurang memiliki pengalaman sebagai salah satu acuan untuk menentukan sikap dan perilaku. Populasi anak di tiap negara kurang lebih $50 \%$, sehingga masalah yang mungkin terjadi pada kelompok tersebut membutuhkan perhatian besar. Anak membutuhkan dukungan dari orang dewasa di sekitar agar setiap hak yang dimiliki dapat terpenuhi (Blair, et al. 2010).

Anak memiliki beberapa hak dalam kehidupan, salah satunya berkaitan dengan kesehatan. Hal ini tercantum pada Pasal 8 Undang-undang Nomor 23 Tahun 2002 tentang Perlindungan Anak yang menyatakan bahwa anak memiliki hak untuk memperoleh pelayanan kesehatan sesuai dengan kebutuhan. Masalah kesehatan yang saat ini sedang menjadi fokus secara global salah satunya berkaitan dengan disabilitas. Penyandang disabilitas sebanyak $80 \%$ berada di negara berkembang. Sepertiga populasi tersebut adalah anak (Kementerian Kesehatan RI, 2014). Majelis Kesehatan Dunia (World Health Assembly) menanggapi hal tersebut dengan mencanangkan program untuk tahun 20142021 dengan tema 'Kesehatan yang lebih baik bagi penyandang disabilitas'. Program ini memiliki tiga tujuan utama. Pertama, meniadakan penghalang sekaligus meningkatkan akses terhadap pelayanan dan program kesehatan. Tujuan kedua adalah memperkuat serta memperluas pemberian rehabilitasi, teknologi alat bantu, dukungan pelayanan dan rehabilitasi berbasis masyarakat. Tujuan ketiga yaitu menyediakan data terkait disabilitas serta hasil penelitian terkait yang lebih relevan dan dapat dibandingkan secara internasional (WHO, 2015).

Peningkatan akses pelayanan menjadi salah satu tujuan pokok dari program peningkatan derajat 
kesehatan penyandang disabilitas. Blair, et al. (2010) menyebutkan bahwa anak penyandang disabilitas mengalami kesulitan dalam melakukan akses terhadap pelayanan kesehatan. Disabilitas dapat meningkatkan kerentanan individu terhadap masalah kesehatan lain sehingga lebih berisiko mengalami beban ganda. Oleh karena itu sangat penting untuk memastikan penyandang disabilitas memperoleh pelayanan yang sesuai agar dapat mencapai status kesehatan optimal.

Jumlah penyandang disabilitas di Indonesia tertinggi pada tahun 2010 ditemukan di Provinsi Jawa Barat, Jawa Timur, Jawa Tengah, Sulawesi Selatan dan Sumatera Utara. Jawa Timur ditempati oleh 2.689.055 penyandang disabilitas (Kementerian Kesehatan RI, 2014). Data BPS tahun 2012 menyebutkan bahwa jumlah anak penyandang disabilitas di Jawa Timur sebanyak 33.932. Jumlah anak penyandang disabilitas di Surabaya tahun 2012 sebanyak 477.

Fasilitas pelayanan kesehatan, terutama Puskesmas, terus diupayakan pemerataan kualitas maupun kuantitasnya di Indonesia, termasuk pada daerah terpencil, tertinggal dan kepulauan. Hal ini bertujuan untuk mempermudah akses masyarakat terhadap pelayanan kesehatan. Namun, pemanfaatan Puskesmas dinilai masih rendah. Berdasarkan data Survei sosial ekonomi nasional (Susenas) tahun 2007, masyarakat yang mengakses Puskesmas hanyasebanyak 33\%, selebihnya menggunakan fasilitas pelayanan kesehatan lain(Bappenas, 2008).

Keberadaan Puskesmas sangat membantu masyarakat untuk memperoleh pelayanan kesehatan karena berada di lokasi yang mudah dijangkau dan pada beberapa wilayah juga ditambahkan dengan Pustu (Puskesmas pembantu). Namun, keterjangkauan ini tidak langsung membuat semua pihak mengakses Puskesmas. Beberapa pihak kurang mempercayai kualitas pelayanan Puskesmas, baik karena pengalaman sendiri maupun dari orang lain. Puskesmas merupakan penyedia layanan kesehatan dasar yang akan menentukan derajat kesehatan masayarakat utamanya melalui kegiatan promotif dan preventif. Apabila pelaksanaan kegiatan tersebut berjalan dengan baik maka angka morbiditas masyarakat akan menurun dan kualitas kesehatan dapat meningkat. Hal ini dapat terwujud apabila masyarakat bekerja sama dan memberikan kepercayaan kepada Puskesmas.

Masalah yang diangkat melalui studi ini yaitu tentang penggunaan Puskesmas dan faktor yang berhubungan dengan hal tersebut pada anak penyandang disabilitas di wilayah Kecamatan Gubeng dan Mulyorejo, Surabaya. Kecamatan Gubeng dan Mulyorejo berada di daerah yang memiliki persentase penduduk penyandang disabilitas tertinggi, yaitu $28,41 \%$ dari seluruh wilayah di Surabaya (Dinas Sosial Kota Surabaya, 2012). Tujuan studi ini adalah untuk mendeskripsikan faktor determinan pemanfaatan Puskesmas pada anak penyandang disabilitas. Manfaat studi ini yaitu memberikan gambaran faktor yang dapat diintervensi untuk meningkatkan akses anak penyandang disabilitas terhadap Puskesmas.

\section{PUSTAKA}


Disabilitas merupakan istilah yang mencakup kondisi pelemahan organ tubuh (impairment) serta keterbatasan dalam beraktivitas dan berpartisipasi (WHO, 2015). Definisi tersebut menggambarkan bahwa disabilitas tidak hanya dilihat dari kondisi tubuh, namun juga merupakan hasil dari interaksi dengan lingkungan. Disabilitas secara sempit dapat diartikan dengan kondisi ketidaksempurnaan fungsi maupun struktur anatomi dan digunakan sebagai istilah untuk menggantikan kecacatan.

Jenis disabilitas dalam pedoman pelaksanaan Susenas tahun 2009 dibagi menjadi tujuh kelompok. Pertama, tuna netra atau gangguan penglihatan, yaitu berupa buta total atau kurang awas dalam melihat meski menggunakan alat bantu dan terdapat penerangan yang cukup. Kedua, tuna wicara atau gangguan bicara, dapat berupa ketidakmampuan berbicara atau pembicaraannya tidak dimengerti (artikulasi tidak jelas). Jenis disabilitas berikutnya yaitu tuna rungu atau gangguan pendengaran,cacat tubuh (kelainan pada tulang, kelumpuhan maupun ketidaklengkapan anggota gerak), serta tuna grahita (gangguan perkembangan kepandaian). Jenis disabilitas yang lain dapat berupa cacat fisik dan mental, yaitu gabungan cacat tubuh dengan tuna grahita. Jenis disabilitas terakhir yaitutuna laras atau gangguan kejiwaan (BPS, 2009).

Individu dapat mengalami satu jenis disabilitas atau lebih. Hal ini berhubungan dengan tingkat kesulitan dalam beraktivitas yang akan dialami individu. Tingkat kesulitan ini dapat dinilai berdasarkan Activity of Daily Living (ADL) atau aktivitas keseharian. ADL pada anak meliputi kegiatan mandi, berpakaian, makan, menggunakan toilet, dan mobilitas (Tean, 2012). Penilaian ADL dapat menggunakan berbagai cara. Hasil penilaian menunjukkan tingkat kesulitan sekaligus kemandirian anak dalam melakukan ADL.

Fasilitas pelayanan kesehatan yang digunakan penyandang disabilitas salah satunya yaitu Puskesmas. Peraturan Menteri Kesehatan Nomor 75 Tahun 2014 tentang Pusat Kesehatan Masyarakat menjelaskan bahwa Puskesmas merupakan penyedia layanan kesehatan yang menyelenggarakan Upaya Kesehatan Masyarakat (UKM) dan Perseorangan (UKP) dengan lebih mengutamakan upaya promotif dan preventif. Tujuan Puskesmas yaitu mewujudkan kecamatan sehat. Puskemas memiliki syarat lokasi yang terdapat pada pasal 10 antara lain yaitu jalur transportasi aksesibel, dilengkapi fasilitas keamanan, serta memperhatikan pengelolaan kesehatan lingkungan. Tenaga kesehatan yang wajib ada di Puskesmas sesuai pasal 16 antara lain yaitu dokter, dokter gigi, perawat, tenaga kesehatan masyarakat dan tenaga laboratorium.

Faktor yang berhubungan dengan akses penyandang disabilitas terhadap pelayanan kesehatan antara lain biaya pelayanan dan transportasi. Ketidakpuasan antara biaya pelayanan dan manfaat kesehatan yang diperoleh dirasakan oleh $32-33 \%$ penduduk secara umum. Ketidakpuasan pada penyandang disabilitas sebesar $51-53 \%$. Biaya transportasi dirasakan terutama di daerah dengan jumlah penyedia layanan kesehatan tidak memadai(WHO, 2014).

Faktor lain yang juga berhubungan dengan akses penyandang disabilitas terhadap pelayanan 
kesehatan yaitu hambatan fisik, berkaitan dengan desain fasilitas kesehatan yang tidak mengakomodasi penyandang disabilitas. Selain itu terdapat pula faktor kemampuan petugas kesehatan yang kurang memadai dalam melayani pasien penyandang disabilitas. Faktor terakhir berhubungan dengan peran pemerintah yang belum maksimal dalam menjamin pelaksanaan peraturan berkaitan dengan hak penyandang disabilitas (WHO, 2014).

Eryando (2007) mengemukakan pendapat tentang akses terhadap pelayanan kesehatan yang dikelompokkan menjadi tiga, yaitu fisik, ekonomi dan sosial. Akses fisik, berkaitan dengan lokasi dan kondisi fasilitas kesehatan. Akses ekonomi, berkaitan dengan kemampuan untuk membayar biaya yang diperlukan dalam pengobatan. Akses sosial, berkaitan dengan hal nonfisik maupun ekonomi yang mempengaruhi pemilihan pelayanan kesehatan, contohnya pengetahuan dan rasa aman.

\section{METODE}

Studi menggunakan pendekatan observasional dengan rancang bangun cross sectional. Sampel tidak memperoleh perlakuan dan studi dilakukan pada satu waktu. Lokasi studi di wilayah Kecamatan Gubeng dan Mulyorejo pada bulan Mei-Juni 2015. Populasi yaitu 160 anak penyandang disabilitas di wilayah Kecamatan Gubeng dan Mulyorejo. Sampel dipilih dengan cara mengunjungi $50 \%$ populasi dan diperoleh sebanyak 44 anak dengan penentuan berdasarkan purposive sampling. Studi dilakukan berdasarkan kesepakatan dengan orang tua karena umur sampel masih kurang dari 18 tahun. Tahap awal studi dilakukan identifikasi karakteristik anak kemudian menentukan jenis disabilitas dan nilai ADL. Tahap berikutnya mengidentifikasi akses anak terhadap pelayanan kesehatan beserta faktor individu dan lingkungan yang kemungkinan berkaitan dengan hal tersebut. Hasil penilaian variabel kemudian diuji menggunakan Pearson Chi-Square. Selanjutnya dilakukan deskripsi hasil dan penambahan fakta yang diperoleh selama studi. Hasil studi hanya menggambarkan kondisi pihak yang terkait, bukan populasi penyandang disabilitas secara umum karena tidak memenuhi syarat generalisasi.

\section{HASIL DAN PEMBAHASAN}

Anak penyandang disabilitas yang ditemui di Kecamatan Gubeng dan Mulyorejo sebanyak $50,00 \%$ berusia diatas 10 tahun dengan distribusi jenis kelamin hampir sama yaitu 59,09\% laki-laki dan $40,91 \%$ perempuan. Anak sudah memiliki akses yang baik terhadap pelayanan kesehatan, namun untuk pemanfaatan Puskesmas dinilsi masih

rendah. Sebanyak 31,82\% menggunakan Puskesmas atau Pustu sedangkan $68,18 \%$ mengakses klinik atau rumah sakit.

Pemanfaatan Puskesmas lebih rendah dibandingkan dengan fasilitas pelayanan kesehatan lain disebabkan oleh beberapa alasan. Sebanyak $38,89 \%$ responden menyatakan tidak mengakses Puskesmas karena lebih percaya pada pelayanan serta obat yang disediakan oleh rumah sakit. Hermawan, et al. (2011) menyatakan bahwa salah satu faktor yang berhubungan dengan kesediaan berobat di Puskesmas Buayan adalah pengalaman kesembuhan. Pengalaman kesembuhan yang 
diperoleh masyarakat di wilayah kerja Puskesmas Buayan dinilai tinggi sehingga kesediaan untuk kembali menggunakan pelayanan kesehatan tersebut cukup besar. Hal ini kemungkinan tidak dialami oleh responden anak penyandang disabilitas sehingga mengakibatkan kepercayaan terhadap pelayanan Puskesmas menjadi rendah.

Faktor lain yang menyebabkan responden tidak mengakses Puskesmas adalah waktu tunggu relatif lama untuk memperoleh pelayanan (22,22\%). Long, et al. (2004) menyatakan bahwa salah satu masalah yang dihadapi anak penyandang disabilitas di pelayanan kesehatan adalah waktu tunggu yang lama. Kondisi ini ditemukan pada penyandang disabilitas fisik (berhubungan dengan penglihatan, pendengaran, kelengkapan dan kemampuan anggota tubuh untuk berfungsi dengan normal) maupun non fisik (berhubungan dengan perkembangan kecerdasan anak). Hasil tersebut sesuai dengantemuan penelitian bahwa waktu tunggu untuk memperoleh pelayanan menjadisalah satu faktor yang berhubungan dengan keputusan pemanfaatan pelayanan kesehatan pada anak penyandang disabilitas.Anak akan merasa kurang nyaman sehingga mudah rewel apabila menunggu terlalu lama. Kristiani, et al. (2015) menyatakan bahwa waktu tunggu berhubungan secara signifikan dengan kepuasan pasien. Kepuasan pasien selanjutnya juga dapat mempengaruhi keputusan untuk kembali menggunakan pelayanan kesehatan tersebut atau tidak.

Tabel 1. Jenis Disabilitas Anak di Kecamatan Gubeng dan Mulyorejo Berdasarkan Pelayanan Kesehatan yang Diakses Tahun 2015.

\begin{tabular}{|c|c|c|c|c|}
\hline \multirow{2}{*}{ Jenis } & \multicolumn{2}{|c|}{ Puskesmas } & \multicolumn{2}{|c|}{ Non Puskesmas } \\
\hline & $\mathbf{n}$ & $\%$ & $\mathbf{n}$ & $\%$ \\
\hline Tuna netra & 2 & 66,67 & 1 & 33,33 \\
\hline Tuna wicara & 1 & 25,00 & 3 & 75,00 \\
\hline Cacat tubuh & 2 & 100,00 & 0 & 0,00 \\
\hline Tuna grahita & 2 & 18,18 & 9 & 81,82 \\
\hline Cacat fisik $>1$ jenis & 6 & 66,67 & 3 & 33,33 \\
\hline Cacat fisik dan non fisik & 1 & 6,67 & 14 & 93,33 \\
\hline Total & 14 & 31,82 & 30 & 68,18 \\
\hline
\end{tabular}

Mayoritas anak di Kecamatan Gubeng dan Mulyorejo mengalami disabilitas yang berhubungan dengan kondisi nonfisik. Hasil uji statistik antara jenis disabilitas dengan akses Puskesmas menunjukkan signifikansi sebesar 0,006 , artinya dua variabel tersebut berhubungan. Anak dengan jenis disabilitas fisik lebih banyak mengakses Puskesmas sedangkan pada nonfisik cenderung menggunakan rumah sakit. Hal ini dapat disebabkan kebutuhan kesehatan penyandang disabilitas nonfisik lebih tinggi dan membutuhkan penanganan lebih kompleks sehingga kurang dapat diakomodasi oleh Puskesmas. Namun, secara umum masalah kesehatan yang dialami penyandang disabilitas tidak jauh berbeda sehingga sebetulnya masih dapat ditangani oleh Puskesmas.

Kebutuhan kesehatan yang berkaitan secara spesifik dengan disabilitas pada anak memang cenderung ke arah kuratif dan rehabilitatif. Anak membutuhkan pertolongan tenaga kesehatan yang memang terlatih untuk memberikan pengobatan atau 
terapi berkaitan dengan kondisi disabilitas yang dialami. Tenaga kesehatan di Puskesmas masih terbatas dalam memberikan pelayanan tersebut. Sebanyak $22,22 \%$ responden yang tidak mengakses
Puskesmas menyampaikan bahwa kebutuhan fasilitas atau pelayanan kurang dapat dipenuhi di tempat tersebut. Hal ini kemudian menjadi penghambat akses anak terhadap Puskesmas.

Tabel 2. Nilai ADL Anak Penyandang Disabilitas di Kecamatan Gubeng dan Mulyorejo Berdasarkan Pelayanan Kesehatan yang Diakses Tahun 2015.

\begin{tabular}{|c|c|c|c|c|}
\hline \multirow{2}{*}{ Nilai ADL } & \multicolumn{2}{|c|}{ Puskesmas } & \multicolumn{2}{|c|}{ Non Puskesmas } \\
\hline & $\mathbf{n}$ & $\%$ & $\mathbf{n}$ & $\%$ \\
\hline $1-6$ & 7 & 20,59 & 27 & 79,41 \\
\hline $7-14$ & 0 & 0,00 & 0 & 0,00 \\
\hline$>14$ & 7 & 0,70 & 3 & 0,30 \\
\hline Total & 14 & 31,82 & 30 & 68,18 \\
\hline
\end{tabular}

Kategori nilai ADL dibagi menjadi tiga, yaitu kesulitan rendah (1-6), sedang (7-14), dan tinggi (>14). Mayoritas anak penyandang disabilitas di Kecamatan Gubeng dan Mulyorejo termasuk dalam kategori kesulitan rendah. Hasil uji statistik antara nilai ADL dengan akses Puskesmas menunjukkan signifikansi sebesar 0,003 , artinya dua variabel tersebut berhubungan. Anak dengan nilai ADL tinggi banyak mengakses Puskesmas sedangkan pada hasil lebih rendah cenderung menggunakan rumah sakit. Anak yang memiliki nilai ADL tinggi berarti mengalami kesulitan besar dalam beraktivitas. Puskesmas secara geografis lebih mudah diakses oleh masyarakat sehingga dapat mengurangi kesulitan untuk mencapai pelayanan kesehatan tersebut. Oleh karena itu, anak dengan kesulitan mobilitas yang tinggi pada studi ini cenderung lebih banyak mengakses Puskesmas.

Anak penyandang disabilitas dengan nilai ADL tinggi pada penelitian ini memiliki akses yang lebih sulit terhadap alat transportasi. Anak yang menggunakan alat transportasi berupa mobil untuk menuju pelayanan kesehatan diketahui sebanyak 16 anak. Sebesar $12,50 \%$ atau 2 anak dari kelompok tersebut memiliki nilai ADL tinggi. Anak dengan nilai ADL tinggi memiliki tingkat kesulitan yang lebih besar dalam beraktivitas sehingga ruang gerak pun menjadi terbatas. Akses anak terhadap pelayanan kesehatan akan lebih mudah jika didukung dengan alat transportasi yang memadai. Namun, anak penyandang disabiitas dengan nilai ADL tinggi pada penelitian ini memiliki akses yang terbatas terhadap alat transportasi, terutama berupa mobil. Hal tersebut kemungkinan dapat menjadi salah satu penyebab anak dengan nilai $A D L$ tinggi lebih banyak mengakses Puskesmas.

Faktor lingkungan yang dikaitkan dengan akses anak penyandang disabilitas terhadap Puskesmas pada studi ini dikelompokkan menjadi dua, yaitu fisik dan ekonomi. Lingkungan fisik terdiri dari jarak dan alat transportasi. Lingkungan ekonomi terdiri dari pendapatan orang tua, status kepemilikan asuransi, biaya kesehatan dan transportasi. 
Tabel 3. Jarak Menuju Lokasi Pelayanan Kesehatan yang Ditempuh Anak Penyandang Disabilitas di Kecamatan Gubeng dan Mulyorejo Tahun 2015.

\begin{tabular}{|c|c|c|c|c|}
\hline \multirow{2}{*}{ Jarak } & \multicolumn{2}{|c|}{ Puskesmas } & \multicolumn{2}{|c|}{ Non Puskesmas } \\
\hline & $\mathbf{n}$ & $\%$ & $\mathbf{n}$ & $\%$ \\
\hline$<1 \mathrm{~km}$ & 3 & 100,00 & 0 & 0,00 \\
\hline $1-3 \mathrm{~km}$ & 6 & 54,55 & 5 & 45,45 \\
\hline $4-6 \mathrm{~km}$ & 3 & 25,00 & 9 & 75,00 \\
\hline$>6 \mathrm{~km}$ & 2 & 11,11 & 16 & 88,89 \\
\hline Total & 14 & 31,82 & 30 & 68,18 \\
\hline
\end{tabular}

Mayoritas anak penyandang disabilitas menempuh jarak yang relatif jauh menuju pelayanan kesehatan. Kelompok yang paling sedikit menempuh jarak terdekat untuk mencapai pelayanan kesehatan. Hasil uji statistik antara jarak dengan akses Puskesmas menunjukkan signifikansi sebesar 0,005, artinya dua variabel tersebut berhubungan. Anak yang mengakses Puskesmas cenderung menempuh jarak lebih dekat dibandingkan dengan menuju rumah sakit. Meski demikian tetap terdapat anak yang menempuh jarak relatif jauh untuk sampai ke Puskesmas. Pada jarak $1 \mathrm{~km}$ atau lebih, jumlah anak penyandang disabilitas yang mengakses Puskesmas lebih rendah dibandingkan dengan rumah sakit. Berdasarkan data ini dapat diketahui bahwa untuk mencapai Puskesmas sebenarnya diperlukan upaya yang lebih ringan. Jarak menentukan waktu tempuh yangdiperlukan untuk memperoleh pelayanan. Oleh karena itu dapat dikatakan bahwa akses menuju Puskesmas lebih mudah. Namun, jarak dapat dipengaruhi oleh faktor lain sehingga dapat memperpendek waktu tempuh. Jadi dapat disimpulkan bahwa jarak berhubungan dengan akses Puskesmas namun bukan faktor utama.

Faktor lingkungan fisik berikutnya yaitu alat transportasi. Hasil studi menunjukkan bahwa anak penyandang disabilitas memiliki akses yang baik terhadap alat transportasi. Mayoritas anak, yaitu $81,82 \%$, menggunakan kendaraan pribadi untuk mencapai lokasi pelayanan kesehatan. Hasil uji statistik antara alat transportasi dengan akses Puskesmas menunjukkan signifikansi sebesar 0,002, artinya dua variabel tersebut berhubungan. Alat transportasi dapat memperpendek waktu tempuh yang diperlukan untuk mencapai pelayanan kesehatan. Hal ini dapat mengatasi kesulitan untuk mencapai lokasi yang jauh. Jadi, meskipun menempuh jarak relatif jauh, apabila akses terhadap alat transportasi lebih mudah maka hal tersebut tidak menjadi masalah.

Hasil penelitian Sartika (2010) mengenai faktor yang berhubungan dengan kesediaan ibu membawa balita ke tempat pelayanan kesehatan diantaranya yaitu jarak dan ketersediaan alat transportasi. Jarak relatif jauh dan alat transportasi yang sulit diperoleh menjadi salah satu alasan para ibu tidak membawa balita untuk mengakses pelayanan kesehatan. Hasil ini sesuai dengan temuan bahwa faktor jarak dan alat transportasi juga berhubungan dengan akses anak penyandang disabilitas terhadap Puskesmas. 
Tabel 4. Faktor Lingkungan Ekonomi Anak Penyandang Disabilitas di Kecamatan Gubeng dan Mulyorejo Berdasarkan Pelayanan Kesehatan yang Diakses Tahun 2015.

\begin{tabular}{|c|c|c|c|c|}
\hline \multirow{2}{*}{ Faktor } & \multicolumn{2}{|c|}{ Puskesmas } & \multicolumn{2}{|c|}{ Non Puskesmas } \\
\hline & $\mathbf{n}$ & $\%$ & $\mathbf{n}$ & $\%$ \\
\hline \multicolumn{5}{|c|}{ Pendapatan orang tua (juta rupiah) } \\
\hline$<1,5$ & 8 & 0,80 & 2 & 0,20 \\
\hline $1,5-3$ & 6 & 0,25 & 18 & 0,75 \\
\hline$>3$ & 0 & 0,00 & 10 & 100,00 \\
\hline Total & 14 & 31,82 & 30 & 68,18 \\
\hline \multicolumn{5}{|c|}{ Kepemilikan asuransi kesehatan } \\
\hline $\mathrm{Ya}$ & 9 & 32,14 & 19 & 67,86 \\
\hline Tidak & 5 & 31,25 & 11 & 68,75 \\
\hline Total & 14 & 31,82 & 30 & 68,18 \\
\hline \multicolumn{5}{|c|}{ Biaya kesehatan per bulan (ribu rupiah) } \\
\hline 0 & 9 & 32,14 & 19 & 67,86 \\
\hline$<50$ & 5 & 100,00 & 0 & 0,00 \\
\hline $50-100$ & 0 & 0,00 & 1 & 100,00 \\
\hline$>100$ & 0 & 0,00 & 10 & 100,00 \\
\hline Total & 14 & 31,82 & 30 & 68,18 \\
\hline \multicolumn{5}{|c|}{ Biaya transportasi per bulan (ribu rupiah) } \\
\hline$<10$ & 12 & 70,59 & 5 & 29,41 \\
\hline $10-50$ & 2 & 11,76 & 15 & 88,24 \\
\hline$>50$ & 0 & 0,00 & 10 & 100,00 \\
\hline Total & 14 & 31,82 & 30 & 68,18 \\
\hline
\end{tabular}

Keterangan: = Menggunakan asuransi kesehatan

Anak penyandang disabilitas mayoritas memiliki orang tua dengan pendapatan Rp 1.500.000,003.000.000,00. Anak dengan orang tua berpenghasilan lebih atau kurang dari rentang tersebut berjumlah sama. Hasil uji statistik antara pendapatan orang tua dengan akses Puskesmas menunjukkan signifikansi sebesar 0,000 , artinya dua variabel tersebut berhubungan. Kelompok anakdengan orang tua berpenghasilan $R p$ 1.500.000,00 atau lebih cenderung mengakses rumah sakit. Puskesmas lebih banyak diakses oleh anak dengan orang tua yang berpenghasilan relatif rendah.Bahkan, anak dengan orang tua yang berpenghasilan lebih dari $\operatorname{Rp} 3.000 .000,00$ sama sekali tidak mengakses Puskesmas. Penghasilan orang tua yang lebih besar membuat pilihan pelayanan kesehatan yang akan diakses menjadi lebih banyak. Pada tahap ini masalah jumlah uang yang harus dikeluarkan bukan lagi menjadi pertimbangan utama, terlebih jika hal tersebut untuk kesehatan anak. Semakin meningkatnya pendapatan maka alokasi biaya kesehatan akan lebih besar dan anak akan lebih cenderung mengakses rumah sakit.

Mayoritas anak penyandang disabilitas pada studi ini sudah memiliki asuransi kesehatan. Anak yang memiliki asuransi kesehatan dan tidak menunjukkan persentase sama pada pemanfaatan Puskesmas maupun rumah sakit. Hasil uji statistik antara kepemilikan asuransi kesehatan dengan akses Puskesmas menunjukkan signifikansi sebesar 0,951, artinya dua variabel tersebut tidak berhubungan. Newacheck, et al. (1996) melakukan penelitian mengenai akses anak terhadap pelayanan kesehatan berdasarkan pendapatan orang tua, ras dan status asuransi. Penelitian Newacheck membandingkan antara anak dari keluarga kurang mampu, minoritas, dan tidak memiliki asuransi kesehatan dengan kelompok kontrol. 
Hasil penelitian Newacheck, et al. (1996) menunjukkan bahwa anak yang berasal dari keluarga kurang mampudibandingkan dengan kelompok kontrol memiliki persentase kunjungan ke pelayanan kesehatan sebesar $44 \%$. Hal ini berarti anak dari keluarga kurang mampu lebih berisiko untuk tidak memperoleh pelayanan kesehatan dibandingkan dengan kelompok kontrol.Hasil penelitian juga menunjukkan bahwa terdapat perbedaan penggunaan pelayanan kesehatan primer antarkelompok berdasarkan pendapatan orang tua dan kepemilikan asuransi. Hubungan antara akses pelayanan kesehatan dengan pendapatan orang tua menunjukkan kesamaan dengan temuan pada penelitian ini. Namun, hubungan antara akses pelayanan kesehatan dengan kepemilikan asuransi kesehatan menunjukkan hasil yang berbeda.Temuan penelitian menyatakan bahwa status asuransi anak penyandang disabilitas tidak berhubungan dengan akses Puskesmas. Anak penyandang disabilitas yang mengakses Puskesmas maupun selainnya menunjukkan persentase sama. Hal ini kemungkinan berhubungan dengan mulai diberlakukannya kebijakan jaminan kesehatan nasional bagi semua warga negara Indonesia sehingga hal tersebut tidak lagi sulit untuk diperoleh.

Biaya kesehatan anak penyandang disabilitas diluar pengguna asuransi mayoritas diatas Rp 100.000,00. Anak yang mengakses Puskesmas membutuhkan biaya kesehatan relatif rendah yaitu kurang dari Rp 50.000,00. Anak yang mengakses selain Puskesmas membutuhkan biaya relatif tinggi yaitu Rp 50.000,00 atau lebih. Hasil uji statistik antara biaya kesehatan dengan akses Puskesmas menunjukkan signifikansi sebesar 0,000, artinya dua variabel tersebut berhubungan.

Biaya transportasi per bulan anak penyandang disabilitas mayoritas antara Rp 10.000,00-50.000,00. Anak yang mengakses Puskesmas mayoritas memerlukan biaya transportasi relatif sedikit, yaitu kurang dari Rp 10.000,00. Anak yang mengakses selain Puskesmas memerlukan biaya relatif lebih besar, yaitu $\mathrm{Rp} 10.000,00$ atau lebih. Hasil uji statistik antara biaya kesehatan dengan akses Puskesmas menunjukkan signifikansi sebesar 0,000, artinya dua variabel tersebut berhubungan.

Hasil Survei Dasar Kesehatan Indonesia (SDKI) tahun 2003 menunjukkan bahwa penyebab keterjangkauan pelayanan kesehatan belum merata salah satunya adalah karena kendala biaya. Biaya kesehatan berpengaruh sebesar $34 \%$ terhadap keterjangkauan pelayanan kesehatan. Biaya transportasi berpengaruh sebesar 16\% (Bappenas RI, 2008). Masalah biaya secara global dipandang sebagai salah satu pembatas antara individu dengan pelayanan kesehatan (WHO, 2014). Meski kesadaran masyarakat terhadap kesehatan sudah meningkat, namun faktor biaya tetap menjadi kendala yang nyata untuk mengakses pelayanan kesehatan. Masyarakat terutama yang berasal dari kelompok ekonomi menengah ke bawah dihadapkan pada pilihan sulit ketika sakit. Pelayanan kesehatan sudah tersedia, akses menuju lokasi tersebut mudah, namun biaya kesehatan dan transportasi tidak tersedia, akhirnya masyarakat tetap tidak dapat memanfaatkan fasilitas yang ada. Namun, saat ini masalah pembiayaan sudah menjadi lebih ringan dengan adanya program asuransi kesehatan dari 
pemerintah. Masyarakat yang kurang mampu menjadi tanggungan negara secara penuh dalam hal pembiayaan kesehatan.

Anak penyandang disabilitas pada studi ini tidak ditemukan mengalami masalah besar dalam hal pembiayaan kesehatan. Semua anak dapat mengakses pelayanan kesehatan. Berdasarkan data pada tabel 7 dan 8 dapat diketahui bahwa besar biaya kesehatan dan transportasi antara anak yang mengakses Puskesmas dan selainnya memiliki selisih relatif besar. Semakin besar biaya yang dapat dialokasikan maka akses terhadap Puskesmas cenderung semakin rendah. Orang tua yang dapat mengalokasikan biaya lebih besar akan lebih mengarahkan anak untuk mengakses rumah sakit. Terlepas dari berbagai faktor lain yang mungkin mempengaruhi, biaya tetap menjadi salah satu faktor paling signifikan yang berhubungan dengan akses terhadap Puskesmas.

\section{SIMPULAN}

Penggunaan Puskesmas pada anak penyandang disabilitas di Kecamatan Gubeng dan Mulyorejo sebesar $31,82 \%$. Hal ini menunjukkan bahwa akses anak penyandang disabilitas terhadap Puskesmas di Kecamatan Gubeng dan Mulyorejo masih rendah dibandingkan dengan pelayanan kesehatan lain. Anak yang cenderung mengakses Puskesmas adalah penyandang disabilitas fisik, memiliki nilai $A D L$ tinggi, menempuh jarak relatif dekat ke pelayanan kesehatan, dan memiliki akses cukup mudah terhadap alat transportasi. Karakteristik lain dari anak penyandang disabilitas yang mengakses Puskesmas yaitu berasal dari keluarga dengan pendapatan menengah ke bawah serta memiliki kebutuhan biaya kesehatan dan transportasi yang relatif rendah. Anak yang tidak mengakses Puskesmas adalah penyandang disabilitas non fisik, memiliki nilai ADL rendah, menempuh jarak relatif jauh ke pelayanan kesehatan dan memiliki akses yang mudah terhadap alat transportasi. Karakteristik lain dari anak penyandang disabilitas yang tidak mengakses Puskesmas yaitu berasal dari keluarga dengan pendapatan menengah ke atas serta memiliki kebutuhan biaya kesehatan dan transportasi yang relatif tinggi.

Saran bagi penelitian selanjutnya yaitu mempertimbangkan penggunaan metode pengambilan sampel secara acak agar hasil dapat digeneralisasi. Selain itu peneliti perlu menilai faktor lain yang mungkin berpengaruh agar pembahasan penelitian menjadi lebih kaya.

\section{DAFTAR PUSTAKA}

Badan Perencanaan Pembangunan Nasional Republik Indonesia. (2008). Peningkatan Akses Masyarakat Terhadap Kesehatan yang Berkualitas. Jakarta: Badan Perencanaan Pembangunan Nasional Republik Indonesia.

Badan Pusat Statistik. (2009). Survei Sosial Ekonomi Nasional. Jakarta: Badan Pusat Statistik.

BadanPusat Statistik Provinsi Jawa Timur. (2013). Provinsi Jawa Timur dalam Angka. Surabaya: Badan Pusat Statistik Provinsi Jawa Timur.

Blair, M., S. S.Brown, T. Waterson, danR. Crowther. (2010). Child Public Health. New York: Oxford UniversityPress.

Dinas Sosial Kota Surabaya. (2012). PMKS/PSKS: Penyandang Cacat. Diakses dari: http://dinsossby.surabaya.go.id/pmks/penyanda ng_cacat.php?data=penyandang_cacat.

Eryando, T. (2007). Aksesibilitas Kesehatan Maternal di Kabupaten Tangerang, 2006. Makara, Kesehatan, 11(2), 76-83.

Hermawan, A., C. Aminoto, dan C. Septiwi. (2011) Analisis Faktor-Faktor yang Berhubungan dengan Masyarakat Berobat di Puskesmas Kecamatan Buayan. Jurnal Ilmiah Kesehatan Keperawatan, 7(2), 91-100.

Kementerian Kesehatan Republik Indonesia. (2014). Penyandang Disabilitas pada Anak. Jakarta: 
Pusat Data dan Informasi Kementerian Kesehatan Republik Indonesia.

Kristiani, Y., A. Sutriningsih, dan V. M. Ardhiyani. (2015). Hubungan Waiting Time dengan Kepuasan Pasien Prioritas 3 di Instalasi Gawat Darurat RS Waluya Sawahan Malang. Jurnal Care, 3(1), 33-38.

Long, S. K. dan T. A. Coughlin. (2004). Access to Care for Disabled Children Under Medicaid. Health Care Financing Review, 26(2), 89-103.

Newacheck, P. W., D. C. Hughes, dan J. J. Stoddard. (1996). Children's Access to Primary Care: Differences by Race, Income, and Insurance Status. Pediatrics,97(1), 26-32.

Peraturan Menteri Kesehatan Republik Indonesia Nomor 75 Tahun 2014. Pusat Kesehatan Masyarakat. 17 Oktober 2014. Berita Negara Republik Indonesia Tahun 2014. Jakarta.

Sartika, R. A. D. (2010). Analisis Pemanfaatan Program Pelayanan Kesehatan Status Gizi Balita. Jurnal Kesehatan Masyarakat Nasional, 5(2), 76-83.

Syukria, O. A. (2015). Faktor yang Berhubungan dengan Akses Anak Penyandang Disabilitas Terhadap Puskesmas. Skripsi. Program S1 IImu Kesehatan Masyarakat Universitas Airlangga. Surabaya.

Tean, S. C. H. (2012). Assessment of Activities of Daily Living in Infants and Children with Developmental Disabilities. The Singapore Family Physician, 38(2), 16-20.

Undang-Undang Republik Indonesia Nomor 23 Tahun 2002.Perlindungan Anak. 22 Oktober 2002. Lembaran Negara Republik Indonesia Tahun 2002 Nomor 109. Jakarta.

World Health Organization. (2014). Disability and Health. Diakses dari: http://www.who.int/mediacentre/factsheets/fs35 2/en/.

World Health Organization. (2015). WHO Global Disability Action Plan 2014-2021. Diakses dari: http://www.who.int/disabilities/actionplan/en/. 